\title{
High-pass-filter cut-offs optimization of the filter-based fatigue index during dynamic contractions
}

\author{
Jungyoon Kim, Sunwoo Park, Youngho Kim ${ }^{*}$
}

From 4th Congress of the International Foot and Ankle Biomechanics (i-FAB) Community

Busan, Korea. 8-11 April 2014

\section{Background}

Traditional muscle fatigue indices $\left(\mathrm{F}_{\text {mean }}\right.$ and $\left.\mathrm{F}_{\text {med }}\right)$ have a relatively low sensitivity under dynamic exercise conditions. Various muscle fatigue indices have been attempted to overcome this problem $[1,2]$. However, their methods required large amounts of computation and had limitations in time-frequency resolution [3]. Kim et al. introduced the use of a filter-based fatigue index $\left(\mathrm{FI}_{\mathrm{hl} \text { rOpT }}\right)$, which the ratio of high-frequency to low-frequency components of EMG power [3]. In this study, we optimized the cut-offs of the
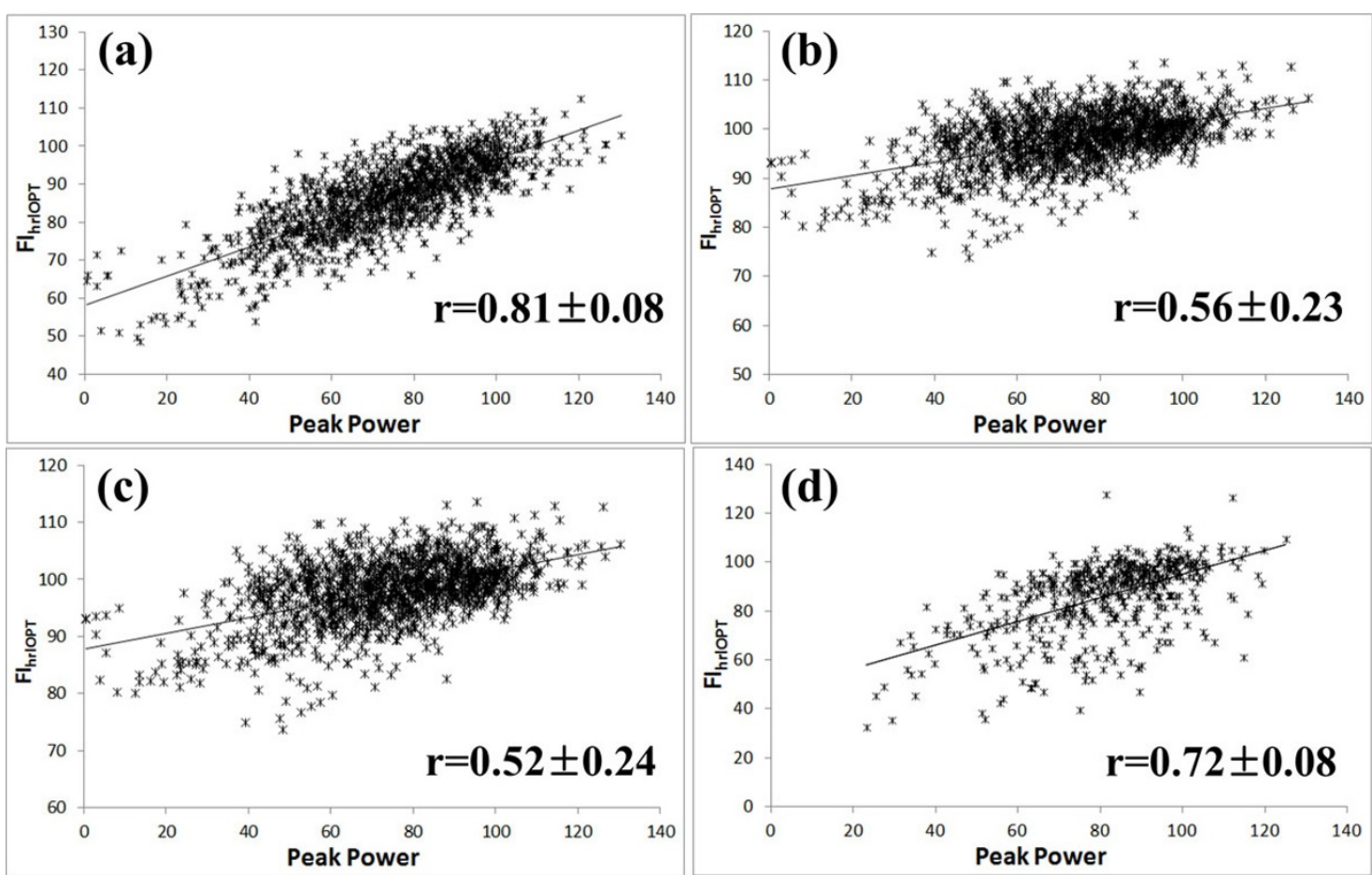

Figure 1 Linear representations of peak power output versus various EMG indices for all subjects. Peak power output versus $\mathrm{FI}_{\text {hlropt }}$ of (a) RF muscle; (b) VM muscle; (c) VL muscle ; (d) BB muscle

\footnotetext{
* Correspondence: younghokim@yonsei.ac.kr

Department of Biomedical Engineering and Institute of Medical Engineering, Yonsei University, Wonju, Gangwon, 220-710, Korea
}

(c) 2014 Kim et al; licensee BioMed Central Ltd. This is an Open Access article distributed under the terms of the Creative Commons 
high-pass-filter (HPF) to maximize the correlation coefficient between the peak power and the $\mathrm{FI}_{\mathrm{hlrOp}}$ in different muscles, and then to determine the frequency bandwidth of our fatigue index.

\section{Methods}

Forty-one healthy males were recruited for this study. Twenty-seven subjects performed knee extension/flexion exercises and fourteen subjects performed elbow flexion/ extension exercises on an isokinetic dynamometer (Biodex System 3, Biodex Medical Systems, NY, USA). 10 repetition maximum was used for fatigue exercises. The experimental protocol was 5 sets of 10 knee extensions and elbow flexion with 2 minutes of rest between sets. EMG signals were obtained from rectus femoris (RF), vastus medialis (VM), vastus lateralis $(\mathrm{VL})$ and biceps brachii $(\mathrm{BB})$ muscles using the Noraxon EMG System (MyoSystem 1200, Noraxon Inc., AZ, USA). EMG signals, as well as biomechanical signals (angle, angular velocity and torque) were simultaneously recorded with a sampling rate of $1 \mathrm{kHz}$. $\mathrm{FI}_{\mathrm{hlrOPT}}$ was calculated and cut-offs of HPF were optimized to maximize the correlation between the peak power and $\mathrm{FI}_{\text {hlrOpT }}$.

\section{Results}

Optimized cut-offs of RF, VM, VL and BB were similar $(353.3 \pm 49.5 \mathrm{~Hz}, 343.9 \pm 34.2 \mathrm{~Hz}, 353.7 \pm 36.1 \mathrm{~Hz}$ and $362.3 \pm 28.2 \mathrm{~Hz}$ ). RF, VM, VL and BB muscles showed good correlation with joint power (correlation coefficient was $0.81 \pm 0.08,0.56 \pm 0.23,0.52 \pm 0.24$ and $0.72 \pm 0.08$ ).

\section{Discussion}

Similar to previous study, cut-offs of HPF of muscles were about $350 \mathrm{~Hz}$ (RF: $360 \mathrm{~Hz}$ in previous study). Similar cutoffs of HPF in different muscles showed the possibility of general cut-off for muscle fatigue estimation. Mills showed that the compound muscle action potential spectrum did not change during fatigue above $200 \mathrm{~Hz}$ [4]. Thus, the high frequency power decreased during fatigue because of the reduced motor unit activation. The low frequency power increased during fatigue because of the elevated motor unit action potential areas. $\mathrm{FI}_{\mathrm{hlrOPT}}$ could reflect the decrease in the peak power during fatigue by these reasons.

\section{Acknowledgement}

This research project was also supported by the Sports Promotion Fund of Seoul Olympic Sports Promotion Foundation from Ministry of Culture, Sports and Tourism (s07201212022012).

Published: 8 April 2014

References

1. Karlsson S, Yu J, Akay M: Time-frequency analysis of myoelectric signals during dynamic contractions. IEEE Trans. Biomed. ENG 2000, 47:229-238.

2. Dimitrov GV, Arabadzhiev TI, Mileva KN, Bowtell JL, Crichton N, Dimitrova NA: Muscle fatigue during dynamic contractions assessed by new spectral indices. Med. Sci. Sports Exerc 2006, 38:1971-1979.
3. Kim J, Park S, Ahn S, Kim Y: A Novel Approach of Defining Fatigue Indices with sEMG Power during Isotonic Contractions. J. Precis. Eng. Manuf 2012, 13:977-983.

4. Mills KR: Power spectral analysis of electromyogram and compounded muscle action potential during muscle fatigue and recovery. J. Physiol 1982, 326:401-409.

\section{doi:10.1186/1757-1146-7-S1-A129}

Cite this article as: Kim et al:: High-pass-filter cut-offs optimization of the filter-based fatigue index during dynamic contractions. Journal of Foot and Ankle Research 2014 7(Suppl 1):A129.

\section{Submit your next manuscript to BioMed Central} and take full advantage of:

- Convenient online submission

- Thorough peer review

- No space constraints or color figure charges

- Immediate publication on acceptance

- Inclusion in PubMed, CAS, Scopus and Google Scholar

- Research which is freely available for redistribution

Submit your manuscript at www.biomedcentral.com/submit 